\title{
Use of Periocular Biometric in Face Recognition
}

\author{
Arun Goel, Alka Jindal
}

\begin{abstract}
Biometrics is a technology to identify people based on their physical and behavioral traits. Enhancement in the field of biometrics have led to development of a trait that is non intrusive, widely acceptable and can be captured remotely with effective features. Face biometric is widely used trait all over world. Due to less efficiency of face biometric in non cooperative environment, researchers suggest to use a sub region of face that is more effective. Periocular biometric is region surrounding the eyes having modalities including eyebrows, eyelashes, eyelids, tear duct and skin texture. This paper explores use of periocular region and its modalities in face recognition including periocular databases and its use in future for various applications.

Index Terms: eyebrow, eyelash, eyelid, face, periocular, skin texture, tear duct
\end{abstract}

\section{INTRODUCTION}

Due to more surveillance, human recognition has become necessity all over the world. Traditional methods of human recognition are time consuming, costly and complex and not error free. This led to development of identifying person using science which uses physical and behavioral traits of person called biometrics. Many traits use for recognition including finger print, face, ear, nose, voice, gait etc. Due to non intrusive, universally acceptable and robust feature, face becomes important biometric trait.

But due to less accuracy in unconstrained wild environments of face biometric led researcher to use a subpart of it which has more distinctive features. Researchers proposed to use periocular region of face. Periocular biometric is region surrounding the eyes having modalities including eyebrows, eyelashes, eyelids, tear duct and skin texture. Periocular region have more robust and discriminative features. Due to small region of face, it takes less time for recognition than face that makes it more reliable. Periocular region [1] proves to be more effective for face recognition captured in visible spectrum where iris recognition fails due to more distance and noise disturbance in environment [2]. Periocular modalities is described in fig 1 . This paper in structured in various sections. Section II contains steps for any biometric trait recognition. Section III describes widely use databases of periocular and its trait. Section IV describes use of periocular region in face recognition. Section $\mathrm{V}$ concludes the paper and give some briefing about future work in periocular biometrics.

Revised Manuscript Received on July 04, 2019.

Arun Goel, Department of Computer Science \& Engineering, Punjab Engineering College, Chandigarh, India.

Alka Jindal, Department of Computer Science \& Engineering, Punjab Engineering College, Chandigarh, India.

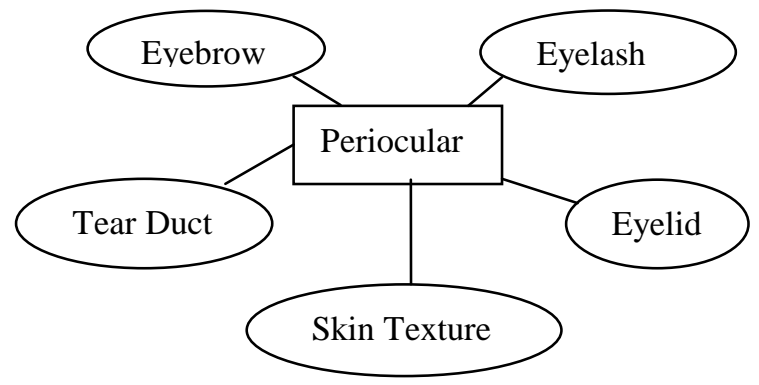

Fig. 1: Periocular Modalities

\section{BIOMETRIC RECOGNITION}

Steps of recognizing any biometric trait is described in figure 2.

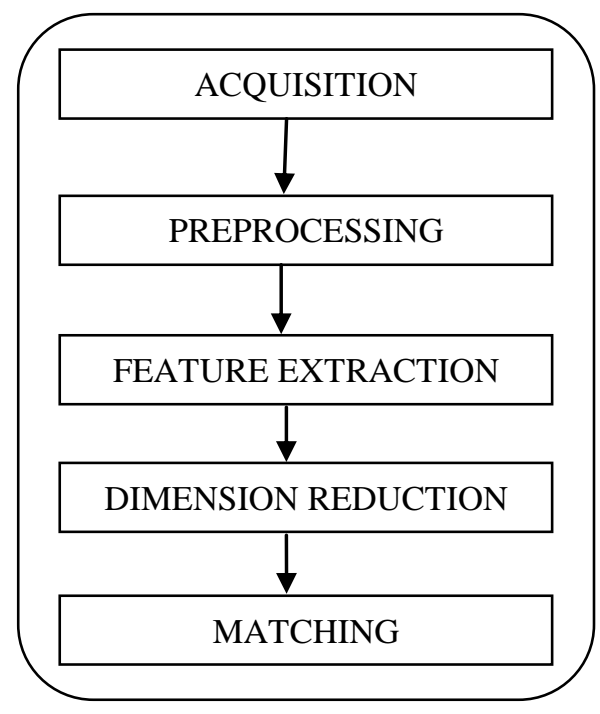

Fig. 2: Biometric Recognition System.

Acquisition: It is first step in which images are captured using cameras of different resolution, wavelength and spectrum.

Preprocessing: After image acquisition, Images are preprocessed to invariant about pose, illumination etc. Pose corrected by applying pose invariant and illumination invariant methods automatically by describing facial landmarks using AAM and ASM and revolve image around centre of eye using Procrustes Analysis. After normalization any biometric trait used for recognition can be found using simple crop on desired region.

Feature Extraction: After preprocessing, features are extracted from biometric region using various local 
and global feature extractor. Global features extract information from entire image or region of interest. Local features extracts information from neighborhood using selected points for key feature.

Dimension Reduction: After feature extraction, dimensionality reduction is applied for optimized feature or for reduced feature set. Then features vectors are stored of input image for further comparison with feature vector of testing image.

Matching: Feature vector are matched for classification or recognition purpose using matching score based on set threshold value. If score is greater than threshold value, then image accepted otherwise rejected.

\section{DATABASE}

Many researchers used various databases for periocular biometrics and its traits. Authors also used face database to recognize face using periocular region from that database. This paper describes most widely used and publicly available datasets of periocular traits.

Databases used for periocular biometric are UBIPr, IMP, CSIP and FOCS. In UBIPr database captured images varies with distance, pose, illumination and occlusion. Images of FOCS database are from NIR videos. Lots of images are of very low quality, due to sensor noise, improper illumination, out-of-focus blur, spectacular reflection and off-angle. Various periocular datasets used my many authors described in table I. IMP database has acquired images in different kind of spectrum like Visible Wavelength (VW), Near Infrared (NIR) and Night Vision. In CSIP images are captured with four different smart phones with different instance.

Table I: Periocular Datasets.

\begin{tabular}{|l|l|l|l|}
\hline Database & $\begin{array}{l}\text { No. of } \\
\text { Subjects }\end{array}$ & $\begin{array}{l}\text { No. of } \\
\text { Images }\end{array}$ & Illumination \\
\hline $\begin{array}{l}\text { UBIPr } \\
{[3]}\end{array}$ & 261 & 10950 & VW \\
\hline FOCS [4] & 136 & 9581 & NIR \\
\hline IMP [5] & 62 & 620 & NIR \\
& & 310 & VW \\
& & 310 & Night Vision \\
\hline CSIP [6] & 50 & 2004 & VW \\
\hline
\end{tabular}

FRGC, FERET, FGNET, MBGC, CASIA are widely used facial databases used for purpose of human recognition using periocular features. Table II describes widely used facial datasets for facial and periocular recognition.

Table II: Facial Databases.

\begin{tabular}{|l|l|l|l|}
\hline Database & $\begin{array}{l}\text { No. of } \\
\text { subjects }\end{array}$ & $\begin{array}{l}\text { No. of } \\
\text { images }\end{array}$ & Variation \\
\hline FRGC [7] & 741 & 36818 & $\begin{array}{l}\text { Distance } \\
\text { Expression, } \\
\text { Lighting }\end{array}$ \\
\hline FERET [8] & 1199 & 14126 & $\begin{array}{l}\text { Expression, } \\
\text { Light, Pose }\end{array}$ \\
\hline FGNET & 82 & 1002 & $\begin{array}{l}\text { Distance, } \\
\text { Expression } \\
\text { Light, Pose }\end{array}$ \\
\hline MORPH & 515 & 1690 & Lighting, \\
\hline
\end{tabular}

\begin{tabular}{|l|l|l|l|}
\hline & & & Occlusion \\
\hline AR [9] & 126 & $>4000$ & $\begin{array}{l}\text { Expression, } \\
\text { Lighting, } \\
\text { Occlusion }\end{array}$ \\
\hline $\begin{array}{l}\text { MBGC v2 } \\
\text { still }\end{array}$ & 437 & 3482 & $\begin{array}{l}\text { Distance, } \\
\text { Expression, } \\
\text { Light, Pose }\end{array}$ \\
\hline $\begin{array}{l}\text { CASIA V4 } \\
\text { distance }\end{array}$ & 142 & 2567 & None \\
\hline $\begin{array}{l}\text { COMPASS } \\
{[10]}\end{array}$ & 40 & 3200 & $\begin{array}{l}\text { Distance, } \\
\text { expression, } \\
\text { Occlusion }\end{array}$ \\
\hline
\end{tabular}

\section{WORK ON FACE RECOGNITION}

\section{A. Using Periocular Region \\ a) FACE RECOGNITION}

However, iris recognition in infrared spectrum and cooperative environment proved to be robust. But in visible spectrum and non cooperative environment, it faces a lot of challenges.

The paper [2] describes face recognition using periocular region when iris recognition affected due to captured at a distance. It detects left and right periocular region of face and extract GIST as global feature and CLBP as local feature. Chi-square distance is used as a classifier.

Jillela and Ross [11] propose face matching against iris image using periocular information. Three techniques are defined. Local Binary Patterns (LBP), Normalized Gradient Correlation (NGC), and Joint Dictionary-based Sparse Representation (JDSR). Experiment performed on 1358 images states that JDSR gives better recognition rate in periocular as compare to iris region.

$\mathrm{J} \mathrm{Xu}$. et al. [12] propose periocular recognition for face matching. Kernel Correlation Feature Analysis (KCFA) along with WLBP is used. Nearest Neighbor Classifier is used. Experiment performed on NIST FRGC dataset shows verification accuracy of $61.2 \%$.

Adams et al. [13] describes type-II feature extraction method which is optimization of type-I feature extraction for periocular biometric recognition. This paper proposed GEFE (Genetic and evolutionary feature extraction) for type-II feature. GEFE use exploratory toolset using GEC interface for generating results. GEFE ssga algorithm was used.

Felix J. Xu et al. [14] describes periocular region has more accuracy as compare to full face when used in face recognition. Experimented performed on FGRC database using local binary pattern feature and chi square distance as classifier.

Woodard et al. [15] propose use of periocular region for biometric identification. It describe left, right and both eye periocular region of both grayscale and color images. Then LBP features are calculated from periocular region. Then various classifiers are used for matching. According to their experiments, City block distance classifier performs best when experiment performed on FGRC dataset.

Joshi et al. [16] propose use of periocular region for recognition. For feature extraction, Gabor filters are used. DLDA used for dimensionality reduction. Parson Probabilistic Neural 
Network (PPNN) classifier is used after feature reduction. PNN is based on Probability distance function and Bayesian classifier which contains four layers for classify function. Experiment performed on MBGC, PUT, GTDB and IITK databases.

The paper [17] describes use of periocular region for human verification. In this right eye regions are mirrored and combined with left eye to form image set. First preprocessing of image is done using pose invariant and illumination invariant features. Right eye mirrored on Left eye for better modeling of variations. Then features are extracted using raw pixel values, LBP features, PCA and using PCA with LBP, Experiment performed on MBGC dataset.

J. Xu et al. [18] describe use of periocular region for age invariant face recognition. It uses Walsh Hadamard Local binary pattern (WLBP) for feature extraction where LBP applied on images after generating Walsh mask. Features are projected using Unsupervised Discriminant Projection (UDP) as classifier which is more robust as compare to SVM. . Experiments performed on FG-NET dataset shows rank-1 identification accuracy of up to $100 \%$. K. Kumar et al. [19] propose use of periocular region in age invariant face recognition. It first preprocess periocular region. Then histogram of LBP features are created from periocular region and its enhanced and denoised version. Then all histograms are concatenated for feature vector and use chi square distance as classifier.

However, periocular biometrics accuracy also suffers when matching periocular region captured in various spectrums like infrared, visible or hyperspectral. Challenges of periocular biometrics in visible spectrum described in [1].

The paper [10] proposed acquisition and recognition of periocular region using COTS(commercial off the shelf) PTZ(Pan Tilt Zoom) camera for non cooperative subjects in unconstrained scenarios. First 79 landmarks are detected for face. Then image normalized using pose correction and illumination normalization. Then features are extracted from periocular region using Walsh hadamard local binary pattern. Then KCFA (kernel class dependence feature analysis) is used for periocular biometric matching. Experiments performed on COMPASS database.

Sharma et al. [5] describes periocular matching in two spectrums infrared and night vision. Features are extracted using pyramid of histogram of gradients from both spectrum images. Then theses features give input to two neural networks and fused for matching. IMP dataset is used which give accuracy of $48 \%$.

Ujair et al. [20] extract periocular region from RGB videos, NIR videos and hyperspectral image cubes. Image set represented using heterogeneous features. Features extracted from periocular using LBP. Then PCA is applied. Experiment performed on various datasets like MBGC, CMU and Umber. Table III describes use of periocular region in face recognition.

\section{b) OTHER APPLICATIONS}

Marko et al. [21] shows use of periocular region in gender identification . LBP used for feature extraction. PCA, LDA and SVM classifiers are used with 5 fold cross validation. Accuracy of above $80 \%$ recognize on Flicker dataset.
Lyle et al. [22] describe use of periocular region for soft biometric like gender, ethnicity, race, weight classification. Experiments performed on FGRC dataset using LBP as features and SVM as classifier states accuracy of $91 \%$ and 93 $\%$ on ethnicity and gender classification using 5 fold cross validation.

F. Xu et al. [23] proposed use of kernel expansion for joint dictionary learning using fastfood transform which helps in context of missing data recovery through kernalize and de-kernalize the image for cross domain reconstruction. For feature function it uses Random Kitchen Sinks which is combination of Walsh Hadamard Matrics and Gaussian RBF. It proposes use of periocular region on occluded face or occlusion on some part of periocular region of face. Experiment performed on FGRC dataset states $95 \%$ accuracy using fastfood method.

Patel et al. [24] describes periocular region in verifying kinship from images captured in the wild. It uses block-based neighborhood repulsed metric learning (BNRML) framework which uses local ternary pattern (LTP) for feature extraction and NRML for distance metric learning. Experiment performed using Fusion of periocular and face biometric using weighted score level fusion on KinFaceW-II [25] dataset provide verification accuracy of $77.05 \%$.

Bigun et al. [26] describes use of periocular region for expression recognition. Local Binary Pattern(LBP), Histogram of Gradients(HOG), Gabor Features(GABOR), Grey level co occurrence matrix(GLCM), Perceptual Descriptors(GIST) used in fusion as feature extraction methods. All features are concatenated in a single feature vector. SVM (Support Vector Machine) is used as classifier. Experiments performed on $\mathrm{CK}+$ [27] dataset shows overall accuracy of $78 \%$ using all descriptors while maximum accuracy of $75 \%$ using only Gabor Feature as compare to LBP, HOG, GLCM, GIST. Table IV describes use of periocular region in other research areas.

\section{B. USING PERIOCULAR MODALITIES}

To enhance accuracy in different spectrums, researcher use skin texture and tear duct modalities of periocular region.

Miller et al. [28] extract skin salient features and represent using local binary pattern. City block distance is used as classifier. Experimental results performed on FRGC and FERET datasets with $90 \%$ recognition rates. This paper suggests that eye folds, contours of eyelids and skin texture of periocular region are more sophisticated for identifying person.

Abandon et al. [29] propose use of tear duct in image to verify left or right iris image of a person. Tear ducts are extracted from ICE iris images. Then window slide over remaining image to generate negative data find in image. In tear duct edges and texture are detected using infrared illumination. Classifiers like PCA, LDA, boosted features and SVM are used for classification.

In further researches for more accuracy, author find best periocular region including eyelids, eyelashes and eyebrow shape. Hollingsworth [30] states that eyelashes, eyelids, tear ducts and eye shape are 
used most frequently to compare periocular region of person. It uses near infrared images of periocular region taken from iris camera when iris quality is poor. Paper described eyelashes and eyelids as most useful feature for periocular region recognition in infrared images. Hollingsworth et al. [31] describe best periocular region in both infrared and visible spectrum. Eyelids and eyelash are two important features of periocular region as compare to skin texture or tear duct.

Kunjur et al. [32] describe eyebrow measure parameters like thickness, pate point of brow. It states pate point of brow vary in sexual and racial differences. It was noted that eyelid dimensions and shape and position of eyebrow vary in different races. Experiments performed on Indian, Chinese and white racial groups states eyebrow measure difference between Indian and Chinese man.

Kong et al. [33] propose accurate iris segmentation using reflection detection and eyelash detection. Edge detector is used to verify eyelashes. Threshold model is used to recognize reflection. First segmentation is done after normalization feature are extracted using wavelet transform. Then matching dissimilarity measure by L1-Normalization.

Dong et al. [34] propose use of eyebrow shape features for biometric recognition. It use three classifiers MD (minimum distance), LDA (Linear Discriminate Analysis) and SVM (support vector machine). First eyebrow segmented, then features are calculated using shape of eyebrow. Then using classifiers results are obtained.

This paper [2] also suggest to use eyebrow shape along with periocular region for more accuracy. This paper [35] describes eyebrow segmentation technique to extract eyebrow shape from an image. Then periocular face is recognized using shape of eyebrow. This paper proposes use of local eyebrow active shape model for eyebrow framework, eyebrow shape matched using chi square distance. Table $\mathrm{V}$ describes use of periocular modalities in face recognition.

\section{USING FUSION OF MODALITIES}

For more accuracy, many researchers propose to fuse ocular modalities. T Tan et al. [36] describes fusion of iris and periocular for remote identification. Leung-Mallik filters are used to extract complex texture features of periocular region for better accuracy First eye image captured. Then iris and periocular segmentation is done. Then normalization is done and feature is extracted. For matching, combined score is check using set threshold value.

Woodard et al. [37] propose to use periocular region along with iris for non ideal images like occluded iris, blur, illumination effect. First periocular features are extracted. Then iris texture features are calculated. Then combined using score level fusion. Experiment performed on MBGC dataset show improve accuracy by fusing iris and periocular region. This paper [38] describes combination of iris and periocular for human identification. Iris features are extracted using wavelets. Periocular features are extracted using local binary pattern. Then both features are fused using discriminative linear discriminate analysis. Euclidean distance used for matching features. Experiment performed on CASIA and UBIRIS dataset show identification accuracy of $95 \%$ on left eye and $96 \%$ on right eye. Table VI describes use of fusion modalities in face recognition

Table III: Periocular region in face recognition

\begin{tabular}{|c|c|c|c|c|c|c|}
\hline 2010 & $\begin{array}{l}\text { Adam } \\
\text { et al. } \\
\text { [13] }\end{array}$ & Periocular & $\begin{array}{l}\text { GEFE, } \\
\text { LBP }\end{array}$ & $\begin{array}{c}\text { GEFE } \\
\text { ssga }\end{array}$ & $\begin{array}{c}\text { FRGC } \\
\text { [39], } \\
\text { FERET } \\
{[8]}\end{array}$ & $\begin{array}{c}\text { FRG } \\
\text { C-92 } \\
\% \\
\text { FERE } \\
\text { T- } 85 \\
\% \\
\end{array}$ \\
\hline 2013 & $\begin{array}{c}\text { Ujair et } \\
\text { al. } \\
{[17]}\end{array}$ & Periocular & LBP & PCA & $\begin{array}{c}\text { MBGC } \\
{[40]} \\
\text { CMU } \\
{[3]} \\
\text { UBIPr }\end{array}$ & $\begin{array}{l}99 \% \\
97 \% \\
99 \%\end{array}$ \\
\hline 2014 & $\begin{array}{c}\text { Joshi et } \\
\text { al. } \\
{[16]}\end{array}$ & Periocular & Gabor & $\begin{array}{l}\text { DLDA, } \\
\text { PPNN }\end{array}$ & $\begin{array}{c}\text { MBGC } \\
\text { [40], } \\
\text { PUT, } \\
\text { GTDB, } \\
\text { IITK }\end{array}$ & $\begin{array}{l}75 \% \\
89 \% \\
89 \% \\
67 \%\end{array}$ \\
\hline 2010 & $\begin{array}{c}\text { Wooda } \\
\text { rd et al. } \\
{[15]}\end{array}$ & Periocular & LBP & $\begin{array}{l}\text { City } \\
\text { Block }\end{array}$ & FRGC & $\begin{array}{c}\text { L-87 } \\
\% \\
\text { R-87 } \\
\% \\
\text { F-91 } \\
\% \\
\end{array}$ \\
\hline 2010 & $\begin{array}{l}\text { Bhard } \\
\text { waz et } \\
\text { al. [2] }\end{array}$ & Periocular & $\begin{array}{l}\text { GIST, } \\
\text { CLBP }\end{array}$ & $\begin{array}{c}\text { Chi } \\
\text { square }\end{array}$ & $\begin{array}{l}\text { UBIRI } \\
\text { S V2 }\end{array}$ & $\begin{array}{c}73 . \\
65 \%\end{array}$ \\
\hline 2012 & $\begin{array}{l}\text { F. xu et } \\
\text { al. [10] }\end{array}$ & Periocular & WLBP & KCFA & $\begin{array}{c}\text { COMP } \\
\text { ASS }\end{array}$ & $60 \%$ \\
\hline 2014 & $\begin{array}{c}\text { Sharma } \\
\text { et al. } \\
\text { [5] }\end{array}$ & Periocular & PHOG & $\begin{array}{c}\text { Neural } \\
\text { Network }\end{array}$ & $\begin{array}{l}\text { IMP } \\
{[41]}\end{array}$ & $\begin{array}{l}48 \%( \\
\text { NIR+ } \\
\text { NW) }\end{array}$ \\
\hline 2019 & $\begin{array}{c}\text { Kumar } \\
\text { et al. } \\
{[19]}\end{array}$ & Aging & LBP & $\begin{array}{c}\text { Chi } \\
\text { square }\end{array}$ & FRGC & $82 \%$ \\
\hline 2011 & $\begin{array}{c}\text { Xu et. } \\
\text { al } \\
{[18]}\end{array}$ & Aging face & WLBP & UDP & $\begin{array}{c}\text { FGNE } \\
\mathrm{T}\end{array}$ & $100 \%$ \\
\hline 2010 & $\begin{array}{l}\text { J. Xu et } \\
\text { al. [12] }\end{array}$ & Periocular & $\begin{array}{l}\text { WLBP, } \\
\text { KCFA }\end{array}$ & $\begin{array}{c}\text { Nearest } \\
\text { Neighbor }\end{array}$ & FRGC & $\begin{array}{l}61 . \\
2 \% \\
\end{array}$ \\
\hline 2011 & $\begin{array}{c}\text { Park et } \\
\text { al. [1] }\end{array}$ & Periocular & $\begin{array}{l}\text { GO, } \\
\text { LBP, } \\
\text { SIFT }\end{array}$ & $\begin{array}{c}\text { Euclidea } \\
\mathrm{n}\end{array}$ & FRGC & $\begin{array}{c}\text { SIFT- } \\
78 . \\
5 \% \\
\text { Overa } \\
11-87 . \\
32 \%\end{array}$ \\
\hline
\end{tabular}


Table IV: Periocular Region in different areas

\begin{tabular}{|c|c|c|c|c|c|}
\hline Year & Author & Feature & Method & Database & Accuracy \\
\hline 2010 & $\begin{array}{c}\text { Markow } \\
\text { et al. } \\
{[21]}\end{array}$ & Gender & $\begin{array}{c}\text { LBP+PCA } \\
/ \\
\text { LDA/SVM } \\
(5 \text { fold } \\
\text { cross } \\
\text { validation }) \\
\end{array}$ & Flickr & $85 \%$ \\
\hline 2010 & $\begin{array}{l}\text { Lyle et } \\
\text { al. [22] }\end{array}$ & $\begin{array}{c}\text { Ethnicity, } \\
\text { Gender }\end{array}$ & $\begin{array}{l}\text { LBP+SVM } \\
\quad(5 \text { fold } \\
\text { cross } \\
\text { validation })\end{array}$ & FRGC [39] & $\begin{array}{c}\text { Ethnicity-91 } \\
\% \\
\text { Gender-93\% }\end{array}$ \\
\hline 2012 & $\begin{array}{l}\text { Jillela et } \\
\text { al. [42] }\end{array}$ & $\begin{array}{l}\text { Surgial } \\
\text { face }\end{array}$ & $\begin{array}{l}\text { Face-verilo } \\
\text { ok, Pittpatt } \\
\text { Periocular- } \\
\text { SIFT, LBP }\end{array}$ & $\begin{array}{l}\text { Plastic } \\
\text { surgery } \\
\text { images }\end{array}$ & $87.4 \%$ \\
\hline 2016 & $\begin{array}{l}\text { F. xu et } \\
\text { al. [23] }\end{array}$ & $\begin{array}{l}\text { Hallucinati } \\
\text { ng face }\end{array}$ & $\begin{array}{l}\text { Fast food } \\
\text { transform, } \\
\text { Random } \\
\text { Kitchen } \\
\text { Sank }\end{array}$ & FRGC & $95 \%$ \\
\hline 2017 & $\begin{array}{l}\text { Aginako } \\
\text { et al. } \\
\text { [43] }\end{array}$ & Mobile id & $\begin{array}{c}\text { LBP, LPQ, } \\
\text { KNN, Bag } \\
\text { of words }\end{array}$ & $\begin{array}{c}\text { VISOB } \\
{[44]}\end{array}$ & $92 \%$ \\
\hline 2017 & $\begin{array}{l}\text { Patel et } \\
\text { al. [24] }\end{array}$ & Kinship & $\begin{array}{c}\mathrm{LTP}+\mathrm{NR} \\
\mathrm{ML}\end{array}$ & $\begin{array}{c}\text { KinFaceW } \\
\text {-II } \\
{[25]}\end{array}$ & $77.05 \%$ \\
\hline 2018 & $\begin{array}{l}\text { A-F et } \\
\text { al. [26] }\end{array}$ & Expression & $\begin{array}{l}\text { LBP, } \\
\text { HOG, } \\
\text { Gabor, }\end{array}$ & CK+ & $\begin{array}{c}\text { Overall-78\% } \\
\text { Gabor+SVM } \\
-75 \%\end{array}$ \\
\hline
\end{tabular}

Table V: Periocular Modalities in face recognition

\begin{tabular}{|c|c|c|c|c|c|c|}
\hline Year & Author & Feature & Algorithm & Classifier & Database & Accuracy \\
\hline 2010 & $\begin{array}{c}\text { Miller et } \\
\text { al. [28] }\end{array}$ & $\begin{array}{c}\text { Skin texture } \\
\text { (both eye) }\end{array}$ & LBP & $\begin{array}{c}\text { City } \\
\text { block distance }\end{array}$ & $\begin{array}{c}\text { FRGC } \\
\text { [39], } \\
\text { FERET[8 } \\
\text { ] }\end{array}$ & $\begin{array}{c}\text { FRGC-89 } \\
.76 \% \\
\text { FERET-7 } \\
4.07 \%\end{array}$ \\
\hline 2014 & $\begin{array}{c}\text { Le et al. } \\
{[35]}\end{array}$ & Eyebrow & LE-ASM & Procrustes & $\begin{array}{c}\text { AR [9], } \\
\text { MBGC } \\
{[40]}\end{array}$ & $\begin{array}{c}\text { AR-76\% } \\
\text { MBGC-8 } \\
5 \%\end{array}$ \\
\hline 2011 & $\begin{array}{c}\text { Dong et } \\
\text { al. } \\
\text { [34] }\end{array}$ & Eyebrow & Shape features & $\begin{array}{l}\text { MD, LDA, } \\
\text { SVM }\end{array}$ & $\begin{array}{c}\text { FRGC } \\
{[39],} \\
\text { MBGC } \\
{[40]}\end{array}$ & $\begin{array}{c}\text { FRGC-B- } \\
75 \% \\
\text { G-97\% } \\
\text { MBGC } \\
\text { B-90\% } \\
\text { G-96\% }\end{array}$ \\
\hline 2011 & $\begin{array}{l}\text { Patel et } \\
\text { al. [45] }\end{array}$ & Pupil & Haar wavelets & $\begin{array}{c}\text { Hamming } \\
\text { distance }\end{array}$ & $\begin{array}{l}\text { CASIA } \\
\text { V1 [46] }\end{array}$ & $94.86 \%$ \\
\hline 2008 & $\begin{array}{c}\text { Savvide } \\
\mathrm{s} \text { et al. } \\
\text { [29] }\end{array}$ & $\begin{array}{l}\text { Tear duct, } \\
\text { iris }\end{array}$ & Haar wavelets & $\begin{array}{l}\text { SVM, PCA, } \\
\text { LDA }\end{array}$ & ICE & $90 \%$ \\
\hline
\end{tabular}

Table VI: Fusion Modalities in Face Recognition

\begin{tabular}{|c|c|c|c|c|c|}
\hline Year & Author & Feature & Method & Database & Accuracy \\
\hline 2012 & $\begin{array}{c}\text { Ross et } \\
\text { al. [42] }\end{array}$ & $\begin{array}{c}\text { Periocula } \\
\mathrm{r}+ \\
\text { Face }\end{array}$ & $\begin{array}{c}\text { SIFT, LBP, } \\
\text { Verilook } \\
\text { Pittpatt }\end{array}$ & $\begin{array}{c}\text { Plastic surgery } \\
\text { Images }\end{array}$ & $\begin{array}{c}\text { Perio-63. 9\% } \\
\text { Face-85. 3\% } \\
\text { Fusion87. 4\% }\end{array}$ \\
\hline \multirow{2}{*}{2012} & $\begin{array}{c}\text { Tan et } \\
\text { al. [36] }\end{array}$ & $\begin{array}{c}\text { Periocula } \\
\mathrm{r}\end{array}$ & $\begin{array}{c}\text { SIFT, LMF, } \\
\text { LG }\end{array}$ & $\begin{array}{c}\text { CASIA V4 } \\
\text { [46] }\end{array}$ & Perio-67\% \\
Iris-64\% \\
\end{tabular}

\section{CONCLUSION \& FUTURE SCOPE}

This paper explore use of periocular biometrics and its various traits in face recognition and some other research areas also. Periocular region emerged to be most useful trait due to robustness and high discriminative features. It also find useful in forensic science to identify criminal whose face is occluded and only periocular region is visible. Periocular region is more tolerant of occlusion and expression and aging variations and more robust than full face matching. This paper described databases of periocular and its traits. This paper described use of fusion modalities for face recognition and also use of periocular region in various other areas. it can be used in future in various aspects like fusion with mouth for better emotion recognition, fusion of more discriminative features and classifiers and use of different databases. In future, effect of wrinkles, makeup, spectacles and skin color can be explored. Also periocular can be used with deep neural networks for finding important features in critical regions of periocular area and to enhance accuracy in case of occlusion and low resolution images

\section{REFERENCES}

[1] U. Park, R. R. Jillela, A. Ross, and A. K. Jain, "Periocular Biometrics in the Visible Spectrum," IEEE Transactions on Information Forensics and Security, vol. 6(1), 2011, pp. 96-106.

[2] S. Bharadwaj, H. S. Bhatt, M. Vatsa, and R. Singh, "Periocular biometrics: When iris recognition fails," in 2010 Fourth IEEE International Conference on Biometrics: Theory, Applications and Systems (BTAS), 2010, pp. 1-6.

[3] "UBIPr, UBI Periocular Dataset." [Online]. Available: http://socia-lab.di.ubi.pt/ ubipr/index.html. [Accessed: 21-Mar-2019].

[4] "FOCS dataset." [Online]. Available: https://cvrl.nd.edu/projects/data/\#face-and-ocular-challenge-series-focs-dat a-collection. [Accessed: 21-Mar-2019].

[5] A. Sharma, S. Verma, M. Vatsa, and R. Singh, "On cross spectra periocular recognition," in 2014 IEEE International Conference on Image Processing (ICIP), 2014, pp. 5007-5011.

[6] "CSIP DataSet." [Online]. Available: http://csip.di.ubi.pt/dbase [Accessed: 21-Mar-2019].

[7] P. J. Phillips et al., "Overview of the Face Recognition Grand Challenge," in 2005 IEEE Computer Society Conference on Computer Vision and Pattern Recognition (CVPR'05), vol. 1, 2005, pp. 947-954.

[8] "FERET dataset." [Online]. Available: https://www.nist.gov/programs-projects/face-recognition-technology-feret. [Accessed: 21-Mar-2019].

[9] "AR Database." [Online]. Available: http://www2.ece.ohio-state.edu/ aleix/ARdatabase.html. [Accessed 21-Mar-2019].

[10] F. Juefei-Xu and M. Savvides, "Unconstrained periocular biometric acquisition and 
recognition using COTS PTZ camera for uncooperative and non-cooperative subjects," in 2012 IEEE Workshop on the Applications of Computer Vision (WACV), 2012, pp. 201-208.

[11] R. Jillela and A. Ross, "Matching face against iris images using periocular information," in 2014 IEEE International Conference on Image Processing (ICIP), 2014, pp. 4997-5001.

[12] J. Xu, M. Cha, J. L. Heyman, S. Venugopalan, R. Abiantun, and M. Savvides, "Robust local binary pattern feature sets for periocular biometric identification," in 2010 Fourth IEEE International Conference on Biometrics: Theory, Applications and Systems (BTAS), 2010, pp. 1-8.

[13] J. Adams, D. L. Woodard, G. Dozier, P. Miller, K. Bryant, and G. Glenn, "Genetic-Based Type II Feature Extraction for Periocular Biometric Recognition: Less is More," in 2010 20th International Conference on Pattern Recognition, 2010, pp. 205-208.

[14] F. Juefei-Xu and M. Savvides, "Subspace-Based Discrete Transform Encoded Local Binary Patterns Representations for Robust Periocular Matching on NIST's Face Recognition Grand Challenge," IEEE Transactions on Image Processing, vol. 23(8), 2014, pp. 3490-3505.

[15] D. L. Woodard, S. J. Pundlik, J. R. Lyle, and P. E. Miller, "Periocular region appearance cues for biometric identification," in 2010 IEEE Computer Society Conference on Computer Vision and Pattern Recognition - Workshops, 2010, pp. 162-169.

[16] A. Joshi, A. Gangwar, R. Sharma, A. Singh, and Z. Saquib, "Periocular recognition based on Gabor and Parzen PNN," in 2014 IEEE International Conference on Image Processing (ICIP), 2014, pp. 4977-4981.

[17] M. Uzair, A. Mahmood, A. Mian, and C. McDonald, "Periocular biometric recognition using image sets," in 2013 IEEE Workshop on Applications of Computer Vision (WACV), 2013, pp. 246-251.

[18] F. Juefei-Xu, Khoa Luu, M. Savvides, T. D. Bui, and C. Y. Suen, "Investigating age invariant face recognition based on periocular biometrics," in 2011 International Joint Conference on Biometrics (IJCB), 2011, pp. 1-7.

[19] K. Kishore Kumar and M. Pavani, "Periocular Region-Based Age-Invariant Face Recognition Using Local Binary Pattern," in Microelectronics, Electromagnetics and Telecommunications, vol. 521, 2019, pp. 713-720.

[20] M. Uzair, A. Mahmood, A. Mian, and C. McDonald, "Periocular region-based person identification in the visible, infrared and hyperspectral imagery," Neurocomputing, vol. 149, 2015, pp. 854-867.

[21] J. Merkow, B. Jou, and M. Savvides, "An exploration of gender identification using only the periocular region," in 2010 Fourth IEEE International Conference on Biometrics: Theory, Applications and Systems (BTAS), 2010, pp. 1-5.

[22] J. R. Lyle, P. E. Miller, S. J. Pundlik, and D. L. Woodard, "Soft biometric classification using periocular region features," in 2010 Fourth IEEE International Conference on Biometrics: Theory, Applications and Systems (BTAS), 2010, pp. 1-7.

[23] F. Juefei-Xu and M. Savvides, "Fastfood dictionary learning for periocular-based full face hallucination," in 2016 IEEE 8th International Conference on Biometrics Theory, Applications and Systems (BTAS), 2016, pp. 1-8.

[24] B. Patel, "Evaluation of periocular features for kinship verification in the wild." Elsevier, Jul-2017.

[25] "Datasets | KinFaceW database." [Online]. Available: http://www.kinfacew.com. [Accessed: 08-Mar-2019].

[26] F. Alonso-Fernandez, J. Bigun, and C. Englund, "Expression Recognition Using the Periocular Region: A Feasibility Study," arXiv:1810.09798 [cs], Oct. 2018.

[27] P. Lucey, J. F. Cohn, T. Kanade, J. Saragih, Z. Ambadar, and I. Matthews, "The Extended Cohn-Kanade Dataset (CK+): A complete dataset for action unit and emotion-specified expression," in 2010 IEEE Computer Society Conference on Computer Vision and Pattern Recognition Workshops, 2010, pp. 94-101.

[28] P. E. Miller, A. W. Rawls, S. J. Pundlik, and D. L. Woodard, "Personal identification using periocular skin texture," in Proceedings of the 2010 ACM Symposium on Applied Computing - SAC '10, 2010, p. 1496.

[29] R. Abiantun and M. Savvides, "Tear-duct detector for identifying left versus right iris images," in 2008 37th IEEE Applied Imagery Pattern Recognition Workshop, 2008, pp. 1-4.

[30] K. Hollingsworth, K. W. Bowyer, and P. J. Flynn, "Identifying useful features for recognition in near-infrared periocular images," in in IEEE Int. Conf. on Biometrics: Theory, Applications, and Systems, 2010, pp. $1-8$.

[31] K. P. Hollingsworth, S. S. Darnell, P. E. Miller, D. L. Woodard, K. W. Bowyer, and P. J. Flynn, "Human and Machine Performance on Periocular Biometrics Under Near-Infrared Light and Visible Light," IEEE
Transactions on Information Forensics and Security, vol. 7(2), 2012, pp. $588-601$.

[32] J. Kunjur, T. Sabesan, and V. Ilankovan, "Anthropometric analysis of eyebrows and eyelids: An inter-racial study," British Journal of Oral and Maxillofacial Surgery, vol. 44(2), 2006, pp. 89-93.

[33] W.-K. Kong and D. Zhang, "Detecting Eyelash and Reflection for Accurate Iris Segmentation," International Journal of Pattern Recognition and Artificial Intelligence, vol. 17(6), 2003, pp. 1025-1034.

[34] Yujie Dong and D. L. Woodard, "Eyebrow shape-based features for biometric recognition and gender classification: A feasibility study," in 2011 International Joint Conference on Biometrics (IJCB), 2011, pp. 1-8.

[35] T. H. N. Le, U. Prabhu, and M. Savvides, "A novel eyebrow segmentation and eyebrow shape-based identification," in IEEE International Joint Conference on Biometrics, 2014, pp. 1-8.

[36] A. Kumar and C.-W. Tan, "Human Identification from at-a-distance Images by Simultaneously Exploiting Iris and Periocular Features," p. 4.

[37] D. L. Woodard, S. Pundlik, P. Miller, R. Jillela, and A. Ross, "On the Fusion of Periocular and Iris Biometrics in Non-ideal Imagery," in 2010 20th International Conference on Pattern Recognition, 2010, pp. 201-204.

[38] A. Joshi, A. K. Gangwar, and Z. Saquib, "Person recognition based on fusion of iris and periocular biometrics," in 2012 12th International Conference on Hybrid Intelligent Systems (HIS), 2012, pp $57-62$.

[39] "FRGC dataset." [Online]. Available: https://cvrl.nd.edu/projects/data/\#face-recognition-grand-challenge-frgc-v2 0-data-collection. [Accessed: 21-Mar-2019].
[40] "MBGC dataset."
[Online].
Available: https://cvrl.nd.edu/projects/data/\#multiple-biometric-grand-challenge-mbg c-version-2-data-collection. [Accessed: 21-Mar-2019].

[41] "IMP Dataset." [Online]. http://www.iab-rubric.org/resources/impdatabase.html. Available: [Accessed: 21-Mar-2019].

[42] R. Jillela and A. Ross, "Mitigating effects of plastic surgery: Fusing face and ocular biometrics," in 2012 IEEE Fifth International Conference on Biometrics: Theory, Applications and Systems (BTAS), 2012, pp. 402-411.

[43] N. Aginako, "Periocular and iris local descriptors for identity verification in mobile applications." Elsevier, 2017.

[44] "VISOB dataset." [Online]. Available: http://sce2.umkc.edu/cibit/dataset.html. [Accessed: 21-Mar-2019].

[45] H. Patel, C. K. Modi, M. C. Paunwala, and S. Patnaik, "Human Identification by Partial Iris Segmentation Using Pupil Circle Growing Based on Binary Integrated Edge Intensity Curve," in 2011 International Conference on Communication Systems and Network Technologies, 2011, pp. 333-338.

[46] "CASIA Databases." [Online]. Available: http://biometrics.idealtest.org/. [Accessed: 24-Feb-2019].

\section{AUTHORS PROFILE}

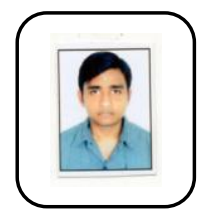

Arun Goel, M.Tech Student in Department of Computer Science \& Engineering, Punjab Engineering College, Chandigarh. His area of interest includes image processing, computer vision, machine learning. Email arungoel142@gmail.com

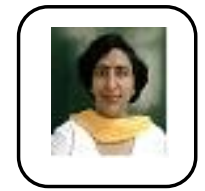

Alka Jindal, Assistant Professor in Department of Computer Science \& Engineering, Punjab Engineering College, Chandigarh. Her area of interest includes image processing, security, database systems Email alka_er@rediffmail.com 